\title{
ARTE E GÉNERO: PINTURAS DE CAPRICCIOSO INGEGNO DE SOFONISBA ANGUISSOLA E DE LAVINIA FONTANA
}

\author{
Fernando António Baptista Pereira
}

Universidade de Lisboa

\section{Resumo}

O nosso texto vai debruçar-se sobre algumas obras de duas importantes pintoras dos séculos XVI e XVII - Sofonisba Anguissola (ca. 1535-1625) e Lavinia Fontana (15521614) - procurando interpretar elementos iconográficos, compositivos e narrativos que constituem as especificidades do modo como cada uma das artistas tenta dar visibilidade a valores femininos, tanto nos assuntos representados como na maneira como os representam. Procuraremos enquadrar todos esses aspetos nos contextos pictóricos de um longo período que assiste, por um lado, à formalização do retrato de corte e à afirmação de uma pintura mitológica cortesã, em ambos os casos dentro da matriz artificiosa e «culta» do que designamos por Maneirismo, e, por outro, à emergência de novos géneros atentos ao «real» (instantâneo, notação do quotidiano, paisagem, natureza morta) que irão marcar toda a posteridade que se convenciona chamar de barroca.

\section{Abstract}

The present text will approach some of the works by two important painters from the 16th and 17th centuries: Sofonisba Anguissola (ca. 1535-1625) and Lavinia Fontana (1552-1614). It will attempt to interpret iconographical, composition and narrative elements which will show how each of the artists tried to manifest feminine values, both in themes and in representation manner. Born to a noble family from Genoa, Sofonisba Anguissola was born in Cremona, a town belonging to Italian territories under Spanish domination. While she was still very young, she became an apprentice in the workshop of the Cremona painter Bernardino Campi, together with her sister Elena, where she served three years. The reputation of her artistic qualities and her accomplished education gained her in 1559 the invitation to the Court of Castile, to serve as the painting teacher of the new wife of Philip II, Elisabeth of Valois, as well as court portrait pain- 
ter. There she would remain until the unexpected death of Elisabeth of Valois in 1568. Sofonisba played a decisive role in the formalization of the Spanish court portrait. On the other hand, Lavinia Fontana was the daughter of Bolognese painter and collector Prospero Fontana, in whose workshop she trained in the taste of late Mannerism, being influenced by Sofonisba Anguissola, the paintings of Northern European masters, with whom she was in touch, and, as well, by the renovation led by the Carracci in her hometown. She married painter Gian Paolo Zappi, with whom she established a greatly successful partnership, both in the affairs of the home (they had eleven children) as well as in the affairs of their workshop (they had orders from several patrons). Our text analyses the most important self-portraits by both painters, which show us how they saw themselves, and especially how they wanted to be seen. There are clear resemblances but also differences. Both present themselves as virtuous maidens, learned and well-versed in the realms of the liberal arts. They are different in their social contexts: Sofonisba, the noble girl with the accomplished education and her main goal to develop her art as portraitist (in a princely court - such as Spain's - as court lady, teacher and artist, albeit not entitled to a professional title) contrasts with the proud executer of a liberal art (and mother) Lavinia, in her productive workshop which somehow continued her father's, counting on her husband to be her main helper and collaborator. Finally, this text will deal with some of the «in action» portraits by Sofonisba, especially with the innovations introduced by the painter to an apparently iconic genre - the court portrait - which she helped to codify and to revolutionize. The text will also deal with two allegorical compositions by Lavinia, where the valuation and exhibition of the female body and feminine attributes become clear.

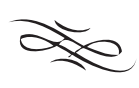

As investigações realizadas nas últimas décadas no âmbito dos estudos de género aplicados às temáticas da História e da História da Arte ${ }^{1}$ revelaram, para além dos dis-

\footnotetext{
$\alpha<\alpha<\alpha<\alpha<\alpha<\alpha<\alpha<\alpha<\alpha<\alpha<\alpha<\alpha<\alpha<$

1 A bibliografia de referência é já numerosa. Para o período que nos ocupa, ver: Merry E. Wiesner, Women and Gender in Early Modern Europe, Cambridge, Cambridge UP, 2000, 2 a ed. [1 ${ }^{\text {a }}$ ed. 1993]; Paola Tinagli, Women in Renaissance Art. Gender, Representation, Identity, Manchester e Nova Iorque, Manchester UP, 1997; Geraldine A. Johnson e Sara F. Matthews (eds.) Picturing Women in Renaissance and Baroque Italy, Cambridge, Cambridge University Press, 1997; Fredrika H. Jacobs, Defining the Renaissance 'Virtuosa': Women Artists and the Language of Art History and Criticism, Cambridge, Cambridge UP, 1999; Claudio Strinati e Joanna Pomeroy, Italian Women Artists from Renaissance to Baroque, cat., Washington DC, National Museum of Women in the Arts, 2007; e Jane Fortune (com Linda Falcone) Invisible Women. Forgotten Artists of Florence, Florence, The Florentine Press, 2009. Especificamente sobre as artistas em questão, ver: Flavio Caroli, ed., Sofonisba Anguissola e le sue sorelle, cat., Milão, Mondadori, 1987; Maria Kusche e Sylvia Ferino-Pagden Sofonisba Anguissola: A Renaissace Woman, cat., Washington DC, National Museum of Women in the Arts/Skira, 1995; Beatriz Porqueres Giménez, Sofonisba Anguissola (c. 1535-1625), Madrid,
} 
tintos modelos de comportamento feminino agenciados pela Literatura e pelas Artes, a existência de inúmeras mulheres artistas nos séculos XVI e XVII. Porém, para mais de metade dos nomes recenseados não se encontra obra identificada ou que possa ser atribuída, uma vez que, na maioria dos casos, estamos perante meras referências em dados documentais ou diante de tópicos em elogios poéticos. Em muitas ocasiões, as obras de autoria feminina foram erroneamente atribuídas a pintores do sexo masculino mais conhecidos na posteridade, como aconteceu com as duas pintoras que abordamos (só para citar alguns exemplos, pinturas de Sofonisba foram anteriormente atribuídas a Ticiano ou a Sanchez Coello, enquanto as de Lavinia foram dadas a Antonis Mor ou a Parmigianino antes de lhe serem assignadas). No sentido inverso, também houve um caso de uma pintora - Josefa de Óbidos - cuja fortuna crítica absorveu a obra do seu pai, Baltasar Gomes Figueira, e só pouco a pouco a obra deste tem sido reconstituída nos últimos anos, graças, principalmente, ao labor de Vitor Serrão ou de Jorge Estrela ${ }^{2}$.

Acresce que a questão da clarificação de percursos artísticos «no feminino» que se diferenciem no seio dos movimentos artísticos de épocas recuadas como a que estamos a tratar não tem sido pacífica. Como já foi amplamente estudado, as fontes disponíveis sobre as mulheres artistas dos séculos XVI e XVII são principalmente constituídas por referências críticas ou elogios poéticos escritos por homens que, se reconhecem a existência de uma nova categoria entre as mulheres, a de artistas, não deixam de sublinhar a superioridade masculina nesse domínio e, de caminho, impõem um certo «acantonamento» da produção artística feminina sob os epítetos de «afectação feminina» ou de «graça feminina» ${ }^{3}$. Está para nós fora de questão «reabilitar» essa estratégia de «acantonamento» da produção artística das duas pintoras que escolhemos, mas tentar surpreender em cada uma delas particularidades de um «olhar feminino» e a maneira como esse modo de estar na pintura singulariza cada uma delas no seu respetivo contexto.

Foi graças ao atrás citado estudo de Fredrika H. Jacobs Defining the Renaissance

Ediciones del Orto, 2003; Maria Teresa Cantaro, Lavinia Fontana bolognese "pittora singolare", Milão-Roma, Jandi Sapi, 1989; Vera Fortunati, ed., Lavinia Fontana 1552-1614, cat., Museo Civico Archeologico di Bologna, 1994; Vera Fortunati, ed., Lavinia Fontana of Bologna, 1552-1614, cat., Milão, Electa, 1998; e Caroline P. Murphy, Lavinia Fontana: A Painter and her Patrons in Sixteenth-century Bologna, New Haven and London, Yale UP, 2003.

2 Cf. Vitor Serrão (org.), Baltazar Gomes Figueira, catálogo da exposição, Óbidos, CMO, 2004, em especial os estudos de V. Serrão e de Jorge Estrela. Não obstante o importante esforço desenvolvido nesse catálogo para separar a obra dos dois pintores, sobretudo ao nível da documentação e das questões de estilo que se reportam à técnica de execução pictórica, não se definiram, a nosso ver, critérios claros para distinguir as composições de cada um dos dois artistas que se integram nos géneros que Baltazar introduziu na Pintura Portuguesa - a Natureza Morta e a Paisagem. Em comunicação que apresentámos num colóquio internacional sobre o Barroco realizado no Porto e que se encontra ainda inédita defendemos, a partir das escassas composições assinadas por cada um dos pintores, que existe um «modo» de compor as naturezas mortas que os diferencia radicalmente: enquanto Baltazar deixa inúmeros espaços «vazios» entre os diferentes elementos, Josefa «preenche» a composição como se se tratasse de um tecido ou tapeçaria.

3 Cf. Fredrika H. Jacobs, Defining the Renaissance 'Virtuosa'..., cit., pp. 1-4. 
'Virtuosa': Women Artists and the Language of Art History and Criticism que esse vasto elenco tanto de nomes como de elogios poéticos permitiu reconhecer que, na Itália do século XVI, os termos mulher e artista não se usavam em conjunto ${ }^{4}$. Com efeito, segundo o que essa autora apurou, as virtudes femininas da primeira eram exactamente o oposto das virtudes masculinas do segundo, o que levou os primeiros escritores que se debruçaram sobre produção artística de mulheres a encontrarem um remédio duplo para resolver esse dilema: por um lado, dividiram o virtuosismo em masculino e feminino; por outro, definiram a virtuosa como uma categoria distinta e excepcional de uma classe mais alargada - a das mulheres em geral ${ }^{5}$. Estas estratégias permitiam continuar a manter a posição de superioridade do masculino ao mesmo tempo que reconheciam o que não se podia negar: que algumas mulheres eram artistas ${ }^{6}$.

Ainda segundo F. H. Jacobs, na esteira, alías, do que outras autoras já tinham intuído ou mesmo demonstrado, a recepção das obras das mulheres artistas no tocante às questões de estilo - la donnesca mano - reflecte, como não poderia deixar de ser, expectativas baseadas nas noções construídas de género. Como ficou demonstrado, a crítica das obras das mulheres artistas fervilha de termos como "diligência", "sentimental", "afectada"; muitas vezes, esses termos são qualificados: a "afectação feminina”, a "graça feminina”. Enquanto mulher e fazedora de arte, a virtuosa renascentista forneceu aos primeiros cronistas dos factos artísticos e aos poetas o veículo perfeito para fundir as definições conflituantes de cada uma delas. Habilmente, os críticos deixaram intacta uma estética que associava a grazia estilística com o domínio masculino do meio. Vasari e Razzi consideravam, por exemplo, que uma virtuosa é uma pintora devota ${ }^{7}$, qualificativo que se colou amiúde à imagem de Sofonisba Anguissola. Num outro caso, assinalava-se uma virtuosa com "capriccioso ingegno", epíteto que também foi aplicado em diversas circunstâncias a Sofonisba. Em contrapartida, Jacobs encontrou nos autorretratos de mulheres uma resposta feminina «diferente» face a tais mensagens verbais, como será provavelmente o caso das pintoras que elegemos, manifestando a recusa de uma mulher em preencher as exigências masculinas de uma tal auto-imagem.

\footnotetext{
$\alpha<\infty<\infty<\infty<\infty<\infty<\infty<\infty<\infty<\infty<\infty<\infty<\infty$

4 Idem, ibidem.

5 Idem, ibidem.

6 Idem, ibidem.

7 Idem, ibidem e, ainda, as pp. 85-122.

8 Giorgio Vasari utiliza esta expressão a propósito de Paolo Uccello (no vol. 3 da Edição Giuntina, p. 62) e uma variante do mesmo - capriccioso e destrissimo ingegno - para se referir a Properzia de Rossi, artista bolonhesa da primeira metade do século XVI. Essa expressão vasariana foi utilizada no subtítulo da Exposição Autorittrate, dedicada à autorrepresentação de artistas mulheres, de Lavinia Fontana aos nossos dias, quadros pertencentes ao famoso Corridoio Vasariano da Galeria degli Uffizi (17 de Dezembro de 2010 a 30 de Janeiro de 2011, Catálogo organizado por Giovana G. Galardi, Florença, Polistampa, 2010). Sobre o conceito de "engenho», sua origem e seus desenvolvimentos no século XVII, ver a nossa entrada homónima in José Fernandes Pereira (ed.), Dicionário de Arte Barroca em Portugal, Lisboa, Presença, 1989, p. 160, e, sobretudo, António José Saraiva, O Discurso Engenhoso, São Paulo, Ed. Perspectiva, 1980.
} 


\section{Duas mulheres artistas de quinhentos, dois distintos percursos biográ- ficos}

Não deixa de ser significativo que Sofonisba Anguissola, apesar de consideravelmente mais velha do que Lavinia Fontana, tenha sobrevivido a esta última ainda vários anos. Interessantes aspetos das respetivas biografias podem ajudar a esclarecer a acentuada diferença de longevidades.

Oriunda de uma família da pequena nobreza genovesa, Sofonisba nasceu em Cremona, cidade então integrada nos territórios italianos sob domínio espanhol. A data de nascimento é ainda desconhecida mas situa-se à volta de $1535^{9}$. Sofonisba recebeu do pai, Amilcare, além do pouco usual nome, que recorda uma célebre heroína de Cartago, cidade de cuja história o progenitor era aficionado, uma esmerada educação humanista, que foi partilhada com as suas irmãs, cujos nomes espelham também o ambiente cultivado vivido pela família: Elena, Europa, Minerva, Lucia...

Ainda muito jovem, Sofonisba realizou uma aprendizagem de três anos, com a sua irmã Elena, na oficina do pintor de Cremona Bernardino Campi, ele próprio formado na famosa oficina de Giulio Romano, discípulo e continuador de Rafael. Campi terá adestrado as duas jovens nas várias modalidades do desenho e na técnica da pintura a óleo. Quando Campi saiu de Cremona, as duas jovens prosseguiram os seus estudos com um outro pintor local, Bernardino Gatti, dito il Soljaro.

Desde muito cedo na sua carreira a jovem Sofonisba despertara a atenção dos meios artísticos como uma espécie de menina-prodígio da pintura ${ }^{10}$. O pai escreveu, em 1557 e 1558, duas cartas a Miguel Ângelo e terá pedido ao mestre um desenho para a filha colorir ${ }^{11}$. A fama das suas qualidades artísticas e da sua esmerada educação (nas

$\infty<\infty<\infty<\infty<\infty<\infty<\infty<\infty<\infty<\infty<\infty<$

9 Cf. Rossana Sacchi, «Sofonisba Anguissola» in Flavio Caroli, ed., Sofonisba Anguissola e le sue sorelle, cat., cit., p. 71.

10 Cf. referência a numerosas obras da jovem pintora que circulavam em Roma, numa carta de Francesco Salviati a Bernardino Campi, professor da artista, recolhida em Flavio Caroli, ed., Sofonisba Anguissola e le sue sorelle, cat., cit., p. 363.

11 Ver as cartas transcritas em Flavio Caroli, ed., Sofonisba Anguissola e le sue sorelle, cat., cit., pp. 364-365. Tommaso Cavalieri conta, numa carta de 1562, que Miguel Ângelo teria visto um desenho de Sofonisba representando uma jovem a rir e que lhe teria escrito mostrando interesse em ver um outro com um putto a chorar, o que levou Sofonisba a enviar-lhe uma composição muito apreciada por Vasari na segunda edição das suas Vite, em concreto na Vita di Properzia de Rossi, descrevendo-a do seguinte modo: «uma jovem ri-se de um menino que chora, porque, tendo-lhe dado um cesto cheio de lagostins, um deles morde-lhe um dedo» (um desenho de Sofonisba com o mesmo assunto subsiste no Museu Capodimonte em Nápoles); antes, Vasari começara por elogiar Sofonisba, nessa data (1568) na corte de Espanha, afirmando que a artista não só tinha desenhado, colorido e tirado do natural e copiado excelentemente coisas de outros mas também tinha ela própria realizado «cose rarissime e bellissime di pittura» (cf. Mina Gregori, «Fama e oblio di Sofonisba Anguissola» in Flavio Caroli, ed., Sofonisba Anguissola e le sue sorelle, cat., cit., pp. 1112). Vasari refere-se uma segunda vez circunstanciadamente a Sofonisba, nas Vite di Benvenuto Garofalo e Girolamo Carpi, relatando uma visita a Cremona onde teve oportunidade de admirar várias composições da pintora, em especial os retratos de membros da família, considerando «che non manchi loro che la parola» (ver a transcrição dos fragmentos de Vasari em Flavio Caroli, ed., Sofonisba Anguissola e le sue sorelle, cat., 
humanidades e na música, de acordo com o que recomendara B. Castiglione para as mulheres da nobreza) valeram-lhe o convite, em 1559, para se dirigir à Corte de Castela para ser a professora de pintura da nova esposa de Filipe II, Isabel de Valois, e retratista áulica. Permaneceria ao serviço da soberana até ao inesperado falecimento desta em 1568, desempenhando um papel decisivo na formalização do retrato de corte espanhol. Nessa data, Alonso Sánchez Coello realizou treze cópias do Retrato do Príncipe D. Carlos pintado por Sofonisba ${ }^{12}$. Como dama da corte da falecida rainha, a pintora deveria retirar-se para o seu país de origem. Porém, terá ficado ao serviço de Joana de Áustria até que Filipe II, em recompensa pelos seus serviços e dedicação, lhe arranjou um vantajoso casamento, com avultado dote, em 1573, com Fabrizio Moncada, que a fez retirar-se para a Sicília, onde viveria cinco anos. Precocemente viúva, em virtude de um acidente sofrido pelo marido (afogado na sequência de um assalto de piratas ao navio em que seguia, ao largo de Capri $^{13}$ ), viria a casar, em Pisa, com o genovês Orazio Lomellini, nos finais de 1579, e, passado algum tempo, radicar-se-ia em Génova até 1615, data em que adquiriu, com o marido, uma grande casa em Palermo, onde ficaria a viver até ao fim dos seus dias (16 de Novembro de 1625). Filipe II e o seu sucessor Filipe III continuaram a protegê-la com o pagamento de uma tença anual. Pouco antes da sua morte, foi visitada, a 12 de Julho de 1624, em busca de conselho, pelo grande retratista Anton Van Dyck, que do acontecimento deixou uma vívida descrição do encontro e um retrato da pintora ${ }^{14}$.

Por seu turno, Lavinia Fontana era filha do pintor e colecionador bolonhês Prospero Fontana, em cuja oficina se formou no gosto do Maneirismo tardio, tendo recebido influência da obra de Sofonisba Anguissola, da pintura de mestres do Norte da Europa, com quem entrou em contacto, nomeadamente Denys Calvaert (1540-1619) ${ }^{15}$, e, também, da renovação que estava a ser protagonizada pelos Carracci na sua cidade natal. A teologia e o imaginário emergente da Contra-Reforma terão sido também uma das suas referências ${ }^{16}$, dominante no meio cultural em que decorrera a sua formação e reforçada com a eleição do bolonhês Ugo Buoncompagni para Papa, sob o nome de Gregório XIII. Por volta de 1578-79 era já conhecida e admirada nos círculos académicos de Bolonha

cit., pp. 404-405)

12 Cf. informação documental recolhida em Flavio Caroli, ed., Sofonisba Anguissola e le sue sorelle, cat., cit., p. 373. Relativamente a seis das cópias o nome de Sofonisba é explicitamente mencionado. Uma delas foi localizada por Annemarie Jordan no Palácio da Vila, em Sintra, posteriormente repintada como Retrato de D. Sebastião. Ver o excelente artigo desta autora «The Image of a King: Court Portraits in the Collection of Philip II», in Pedro Navascués Palacio (ed.), Philippus II Rex, Madrid, Lunwerg ed., 1998, pp. 53-68.

13 Ver os relatos transcritos em Flavio Caroli, ed., Sofonisba Anguissola e le sue sorelle, cat., cit., pp. 382-383.

14 Ver o relato transcrito em Flavio Caroli, ed., Sofonisba Anguissola e le sue sorelle, cat., cit., p. 401 e a reprodução da folha do Diário do artista com o retrato da pintora na p. 32.

15 Cf. Vera Fortunati, «Lavinia Fontana. Una pittrice nell'autunno del Rinascimento» in Lavinia Fontana 1552-1614, cat., Museo Civico Archeologico di Bologna, 1994, pp. 14-20.

16 Cf. Caroline P. Murphy, Lavinia Fontana: A Painter and her Patrons in Sixteenth-century Bologna, New Haven and London, Yale UP, 2003, especialmente a introdução «Art and Society in Sixteenth-century Bologna». 
e Roma ${ }^{17}$. Casou com o também pintor Gian Paolo Zappi, com o qual formou uma parceria de grande êxito, tanto no governo do seu lar (teve onze filhos) como na resposta a numerosas encomendas dos mais diversos comitentes. Dedicando-se preferencialmente à chamada Pintura de História, tanto a grandes retábulos devocionais (no que terá sido a primeira mulher a realizá-los), como a pequenos painéis de temática mitológica ou alegórica, Lavínia tornou-se também conhecida por realizar retratos de personalidades do seu tempo e, ainda, composições de temática feminina, destinadas a uma exigente clientela de mulheres nobres de Bolonha que desejava ser retratada pela pintora ${ }^{18}$. Viveu em Roma, sob o pontificado de Sixto V, que decorreu de 1580 a 1595, e nos últimos dez anos da sua vida, de 1604 a 1614, tendo servido de inspiração à jovem Artemísia Gentileschi ${ }^{19}$.

\section{Autorretratos de Sofonisba e Lavinia}

Os autorretratos das duas pintoras dão-nos a conhecer o modo como cada uma delas se via e, sobretudo, se queria dar a ver. Há claras semelhanças mas também acentuadas diferenças. Ambas se apresentam como virtuosas donzelas, cultas, versadas nos domínios das artes liberais. Sofonisba, em dois dos seus mais antigos autorretratos, insiste, nas inscrições que acompanham a imagem, no seu estatuto de virgo: no de Viena, de 1554, a inscrição aparece sobre um livro que ostenta na mão, sublinhando a sua condição de letrada; no de Boston, de 1555-56 (Fig. 1), realizado sob a influência de Giulio Clovio, a mesma referência aparece rodeando o medalhão com o criptograma do nome do pai (Amilcare), subtil referência às supostas longínquas origens cartaginesas da família, acompanhada da indicação de que o retrato foi realizado a partir de um espelho, num conjunto que faz jus ao "caprichoso engenho» da artista. Nos dois autorretratos ao cavalete (uma versão em menores dimensões numa coleção italiana e a versão maior no museu da cidade polaca de Lancut [Fig. 2], a que se deverá acrescentar uma derivação muito curiosa na coleção F. Zeri ${ }^{20}$ ), realizados entre 1554 e 1556, a artista aparece a pintar uma pequena pintura devocional da Virgem com o Infante Jesus, num alongamento e pose das figuras tipicamente ao gosto maneirista, evidenciando com orgulho e de forma

$\infty<\infty<\infty \times \infty \times \infty \times \infty \times \infty<\infty<\infty<\infty<\infty<\infty$

17 Cf. Maria Teresa Cantaro, Lavinia Fontana bolognese "pittora singolare", cit., p. 11.

18 Cf. Caroline P. Murphy, op. cit., capítulos dois e três, respectivamente «Pictures for Scholars, Prelates, Poets and Bankers» e «'Gentildame et honeste matrone': Representing the Bolognese Noblewoman».

19 Cf. Andrea Bayer em North of the Apennines. Sixteenth-Century Italian Painting in Lombardy and EmiliaRomagna, The Metropolitan Museum of Art Bulletin, Primavera de 3003, p. 47.

20 Ver as imagens no catálogo Sofonisba Anguissola e le sue sorelle, cit., pp. 67, 199 e 201, assim como o texto e as fichas respetivas, pp. 64 e 198-200. Devem ser mencionados, entre vários outros autorretratos, anteriores e posteriores à sua partida para Espanha, dois muito semelhantes, um pertencente ao Museu Brera de Milão e outro existente no comércio de arte (e apresentado por Ilaria Bianchi in Vittorio Sgarbi et alt (eds), L'Arte delle Donne. Dal Rinascimento al Surrealismo, Milão, Pal. Reale, 2007, pp. 330-331, ilustração na p. 74), que deverão datar de 1559, antes da saída de Sofonisba para Castela, como apurou, no caso do primeiro, Valerio Guazzoni, in Flavio Caroli, ed., Sofonisba Anguissola e le sue sorelle, cat., cit., p. 224. 
ostensivamente naturalista - em contradição com a marca «maneirista» do quadro que está a ser pintado - os instrumentos da sua arte. Assinale-se que na derivação, mais tardia, destinada possivelmente a uma galeria de mulheres ilustres, uma inscrição poética no topo, comparando a pintora ao mítico Apeles e às musas, alude ao tópico ut pictura poesis ${ }^{21}$. Finalmente, um outro autorretrato (no Museu Capodimonte, em Nápoles), mostra-nos Sofonisba a tocar a espineta, completando a imagem da artista versada nas artes liberais - música, poesia e pintura ${ }^{22}$.

Este mesmo desiderato foi perseguido por Lavinia Fontana nos seus dois mais conhecidos autorretratos. Naquele que pintou, em 1577 (Fig. 3), valendo como um retrato de casamento, estado a que aspirava e no qual a jovem artista acalentava legítimas expectativas de ascensão social (Museu da Academia de S. Lucas, Roma) ${ }^{23}$, Lavinia representou-se vestindo de vermelho (a cor escolhida pelas noivas em Bolonha), a tocar uma espineta, acompanhada por uma criada que sustenta a partitura, com o seu cavalete de pintura bem visível ao fundo. $\mathrm{Na}$ inscrição latina ao alto define-se como virgo e filha de Prospero Fontana, o que, em conjunto com a exibição do cavalete, manifesta um claro orgulho nas suas origens no meio artístico, indicando, ainda, que o retrato foi realizado a partir de um espelho (tal como mencionara Sofonisba), outra referência explícita aos seus dotes artísticos. Já casada, Lavinia voltou a retratar-se, em 1579 (Fig. 4), num

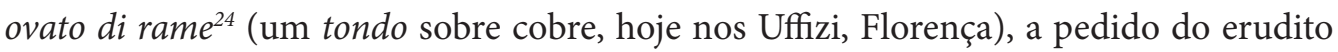
dominicano espanhol Alfonso Chacón, que o pretendia juntar ao mesmo tipo de retrato de Sofonisba que já possuía e editar uma coletânea com retratos gravados de quinhentas figuras de varões e donas ilustres ${ }^{25}$. Neste retrato, Lavinia representa-se ricamente vestida, sentada numa cadeira de braços (outro sinal de distinção social), junto de uma mesa onde pousa o seu braço, segurando na mão uma ponta seca, junto de um maço de papéis. Vê-se, ainda, um tinteiro com uma pena. Em redor, estão pousados e pendurados modelos e moldagens de escultura clássica. Uma vez mais, na imagem de uma mulher

$\infty<\infty<\infty<\infty<\infty<\infty<\infty<\infty<\infty<\infty<\infty<$

21 Cf. Flavio Caroli (ed), Sofonisba Anguissola e le sue sorelle, cit., p. 201, assim como a ficha respectiva, p. 200.

22 Ver a ficha de Rossana Sacchi in Flavio Caroli (ed), Sofonisba Anguissola e le sue sorelle, cit., pp. 202-203.

23 Caroline Murphy, op. cit., p. 40, defende que o quadro foi pintado para o futuro marido, Gian Paolo Zappi, tendo em vista a iminente chegada do sogro de Lavinia, Severo Zappi, embora, na realidade, nada na composição ligue a pintura à Família Zappi, ao contrário do que acontece com o autorretrato pintado dois anos depois, em que a artista já ostenta o sobrenome da sua nova família.

24 A tradução de un ovato di rame deverá ser a de um oval em cobre, mas, na realidade, o autorretrato de Lavinia é um tondo. Ver, sobre um dos mais interessantes retratos de Lavinia nesse formato, o de um Padre Jesuíta (embora não identificado como tal, nem pela autora, nem pelo Museu), a interessante leitura de Andrea Bayer em North of the Apennines. Sixteenth-Century Italian Painting in Lombardy and Emilia-Romagna, The Metropolitan Museum of Art Bulletin, cit., pp. 47-48.

25 Sobre os dois retratos aqui referidos, ver Catherine King, "Italian Artists in Search of Virtue, Fame, and Honour c. 1450-c.1650," in The Changing Status of the Artist, eds. Emma Barker, Nick Webb e Kim Woods, London, Yale University Press, 1999, pp. 72-74, e, sobretudo, Babette Bohn, "Female Self-Portraiture in Early Modern Bologna," in Renaissance Studies 18, no. 2 (2004), pp. 251-256. 
artista, se associam a prática do desenho, as letras e o conhecimento e inspiração na cultura artística do mundo clássico. A inscrição latina, além da data, acrescenta o sobrenome Zappi ao seu nome de solteira, sublinhando o seu novo estatuto familiar e social.

Entre as diferenças que encontramos nas imagens que de si procuraram dar as duas pintoras, temos, em primeiro lugar, uma clara inscrição nos distintos contextos sociais de partida: a menina nobre de esmerada educação humanista Sofonisba e o seu principal objetivo para desenvolver a sua arte enquanto retratista - uma corte principesca (como a de Espanha), como dama da corte, professora e artista, embora sem direito a um título profissional - em face da orgulhosa executante de uma arte liberal (e mãe) Lavinia, na sua prolífica oficina, que, de algum modo, continuou a do seu próprio pai, tendo no marido o seu principal ajudante e colaborador.

As diferenças nesses contextos sociais de partida prolongar-se-iam ao nível da clientela, trabalhando Sofonisba principalmente como retratista para a corte de Espanha e para grandes famílias da alta nobreza, embora também tenha realizado pequenos quadros religiosos para devoção privada e não retábulos para igrejas, enquanto Lavinia respondeu, como qualquer outro artista do seu tempo, a uma enorme diversidade de comitentes, sobretudo na sua cidade natal, Bolonha, e em Roma, tanto religiosos como laicos, e, entre estes, a uma específica clientela de mulheres nobres que ansiava ser por ela retratada.

Recentemente, foi revelado o que poderá ser um autorretrato de Lavinia numa das suas últimas gravidezes, datável, portanto, da década de 1590. A especialista da obra de L. Fontana Vera Fortunati atribuiu-a à pintora, corrigindo uma anterior atribuição a Scipione Pulzone feita por Caroline Murphy, e uma outra grande especialista da biografia e obra da artista, Maria Teresa Cantaro, confirmou-a, aceitando que se trate de um autorretrato $^{26}$. Vemos nesta obra não apenas o reforço de uma autoimagem de mãe que a pintora deseja orgulhosamente assumir, mas também a confirmação do particular interesse da pintora em temas que exploram aspetos do mundo circunscrito da feminilidade, como a representação de recém-nascidos no berço, a expressão de afetos protagonizados por mulheres ou a exposição do próprio corpo feminino como expressão diferencial de feminilidade e dos seus atributos e não como mero objeto de desejo, em composições alegóricas e mitológicas, como veremos a seguir.

$\infty<\infty<\infty<\infty<\infty<\infty<\infty<\infty<\infty<\infty<\infty<\infty<$

26 Ver a fortuna crítica recenseada pela casa Dorotheum, no seu site (www.dorotheum.com), com destaque para o texto de Vera Fortunati "Toward a History of Women Artists in Bologna between the Renaissance and the Baroque: Additions and Clarifications", in Italian Women Artists from Renaissance to Baroque, Washington D. C., National Museum of Women in the Arts, Março-Julho de 2007, pp. 45 e 47 . Além de Maria Teresa Cantaro (que publicara o livro de notas do marido de Lavinia com os nascimentos e batismos dos seus onze filhos, nascidos entre 1578 e 1595, em Lavinia Fontana bolognese "pittora singolare", cit., pp. 304-305), confirmou a atribuição Massimo Pulini, que considera o quadro datável de 1592. 


\section{Dos engenhosos retratos «em ação» de Sofonisba às composições ale- góricas de Lavinia}

No final da década de 1550, Sofonisba quis homenagear o seu primeiro mestre realizando um dos seus mais «engenhosos» retratos, o que representa Campi a retratá-la (Fig. 5). Allen Farber, no site em que reúne as suas palestras e aulas, começa por comentar este retrato lembrando as judiciosas observações de Barbara Freedman a propósito da encenação das relações entre observador e observado, tal como se apresentam na famosa gravura de Dürer que ilustra o modelo perspéctico de um pintor representando uma mulher nua: o observador habitualmente identifica-se com a perspectiva masculina do olhar e a mulher como o objecto desse mesmo olhar, numa reinscrição da oposição entre razão e sexualidade, entre activo e passivo, entre o ver e o mostrar. Segundo Allen Farber, Sofonisba, neste seu autorretrato, complicou ainda mais essas relações, ao fazer Campi desviar o olhar do quadro, na nossa direção, onde supostamente estaria o modelo que retrata: nestas circunstâncias, nós ocupamos o lugar da própria Sofonisba, que será a verdadeira autora da pintura mas é também subentendida como modelo, tornando-se simultaneamente sujeito e objecto do retrato, observador e observado. Acresce que, neste retrato duplo, encontramos algumas das inovações de Sofonisba no género, ao introduzir, como notou Mina Gregori ${ }^{27}$, referências cultas ao quadro dentro do quadro, à ekphrasis e, sobretudo, ao real quotidiano e à ação: Campi, cuja presença é sinal de continuidade no magistério e de legitimação da virtuosa no exercício da pintura ${ }^{28}$, é surpreendido numa espécie de instantâneo, interrompendo o seu gesto e a olhar para a modelo, o que antecipa, como vamos ver também no Retrato de Alexandre Farnese, a categoria de «instante» que só iríamos ver emergir no espaço-tempo figurativo do Barroco com a obra de Caravaggio ${ }^{29}$.

Deixando de lado os vários exemplos de «retratos em ação» que Sofonisba realizou, antes e depois da sua estada em Espanha, como os interessantes retratos de família, tão apreciados por Vasari, ou os retratos de crianças nobres, que denotam um gosto pela circunstancialização dos modelos que é único no seu tempo e revela uma atenção particular (e distintamente «feminina», diríamos nós) a detalhes que revelam aspetos das biografias das personalidades e do seu contexto quotidiano e, por vezes, relações afetivas, privilegiemos as inovações trazidas pela pintora a um género aparentemente «icónico» que ajudou a codificar e também a revolucionar - o retrato de corte. O exemplo cimeiro de antecipação da categoria de instante ligada à notação psicológica e às referências ao «real» no género é, como já demos a entender, o Retrato de Alexandre Farnese, hoje

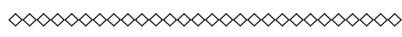

27 Cf. Mina Gregori, «Fama e oblio de Sofonisba Anguissola» in Flavio Caroli (ed), Sofonisba Anguissola e le sue sorelle, cit., pp. 34-35.

28 Cf. Idem, ibidem.

29 Ver, sobre esta categoria, o nosso texto «Da narrativa na Arte. Espaço-tempo figurativo e Istoria na pintura pós-medieval» in Isabel Matos Dias et al. (eds), Estética e Artes. Controvérsias para o Século XXI. Colóquio Internacional, Maio 2003, Lisboa, Centro de Filosofia da FLUL, 2005, pp. 277-301. 
em Dublin (Fig. 6). Faz parte de um conjunto de retratos a três quartos que Sofonisba pintou, nos primeiros anos da sua estada em Espanha, da Rainha e de Príncipes da Família Real ${ }^{30}$. Nesse notável retrato, o jovem príncipe italiano, elegantemente trajado e envergando uma opulenta capa de tecido lavrado, minuciosamente pintada, virando-se para o espetador, é como que surpreendido num gesto de puxar uma luva. Uma cópia do retrato foi enviada para Itália e a efígie do príncipe constante do mesmo seria reproduzida por Taddeo Zuccari no teto afrescado da Sala dei Fanti do Palácio Farnese, em Caprarola $^{31}$, significativamente sem qualquer referência ao gesto instantaneamente capturado na obra de Sofonisba. A pintora viria a retomar um gesto semelhante num retrato mais tardio, o famoso Dama de Arminho da Pollock House de Glasgow (na realidade, a Infanta Catarina Micaela vestindo um abafo de lince ${ }^{32}$ ), em que a retratada puxa com a mão uma das bandas do seu casaco.

Lavinia Fontana também introduziu inovações no género retrato ao desenhar e pintar, com enorme subtileza e ternura, num misto de retrato de figura nobre e de registo de curiosidade científica, a ainda hoje insólita figura de Antonieta Gonzales ou Gonçalvus. O pai de Antonieta, Pedro, originário de Tenerife, nas Canárias, e os seus filhos padeciam de hirsutismo (hypertrichosis universalis congénita), sendo, por esse motivo, objeto de curiosidade médica e artística nas cortes do final de quinhentos, nomeadamente na de Henrique II e Catarina de Medicis e, mais tarde, na dos Farnese, em Parma ${ }^{33}$.

Para terminar, debrucemo-nos sobre duas composições alegóricas de Lavinia Fontana, no contexto da sua resposta multiforme a uma clientela de mulheres nobres e de mecenas de Bolonha e Roma, que implicaria importantes novidades, que aqui não poderemos desenvolver, nos retratos de grupo e individuais, nas variadas realizações retabulares e em pequenas pinturas de temática mitológica ou alegórica.

As duas composições deste último grupo que vamos abordar são Minerva vestindo-se (Fig. 7), realizada para o Cardeal Cipião Borghese na tardia data de 1613, e a Alegoria da Prudência (ou da Pintura ?) (Fig. 8), pintada, ao que tudo indica, cerca de 1590. Apesar da distância de mais de vinte anos entre elas, um fio condutor parece uni-las: a exposição e valorização da feminilidade.

No caso da pintura que representa a Deusa da Sabedoria e da Guerra Estratégica -

$\infty<\infty<\infty<\infty<\infty<\infty<\infty<\infty<\infty<\infty<\infty<\infty$

30 Cf. Maria Kusche «Sofonisba Anguissola al servizio del ré di Spagna» in Flavio Caroli (ed), Sofonisba Anguissola e le sue sorelle, cit., pp. 98-99.

31 Ver a ficha do quadro por Maria Kusche in Flavio Caroli (ed), Sofonisba Anguissola e le sue sorelle, cit., pp. 238-241.

32 Esta é a identificação proposta por Maria Kusche, no texto atrás citado, in Flavio Caroli (ed), Sofonisba Anguissola e le sue sorelle, cit., p. 111.

33 Sobre Pedro Gonçalvus e seus filhos, ver o recente estudo de Merry Wiesner-Hanks, The Marvelous Hairy Girls: The Gonzales Sisters and Their Worlds, New Haven and London, Yale UP, 2009. A doença de que Pedro Gonçalvus e os seus filhos padeciam provocava o crescimento de pêlos em todo o corpo, inclusive no rosto e nas mãos. Foi levado para Paris ainda na infância e exibido na corte de Henrique II. Segundo um relato da época, aí «desaprendeu seus costumes selvagens e aprendeu as belas-artes e a falar latim». Acabaria por casar com uma holandesa, com quem teve filhos, que herdaram a doença. Foi examinado por dois médicos, um dos quais de Bolonha. 
Minerva - a figura, completamente nua e ligeiramente de costas, embora de rosto virado para o espectador, pega em vestimentas femininas, enquanto os seus atributos guerreiros - e masculinos: o escudo, a armadura e o elmo - se encontram espalhados pelo chão, sendo o último agarrado por um putto. Numa grande clareza narrativa, própria de um sentimento naturalista afim do emergente gosto barroco, é como se a Deusa deliberadamente se despisse da sua dimensão masculina para abraçar a sua ostensiva feminilidade.

Já na intitulada Alegoria da Prudência (ou da Pintura?), revelada recentemente por Alessandro Zacchi ${ }^{34}$ e por ele atribuída a Lavinia Fontana, no que obteve a concordância de outros especialistas, nomeadamente Vera Fortunati, a exibição da feminilidade é mediada por uma complexa teia de significados simbólicos, muito ao gosto do Maneirismo tardio, prevalecente em certos círculos da Bolonha de final de Quinhentos. Segundo Zacchi, Lavinia inspirou-se em composições de Lorenzo Sabatini e de Denys Calvaert representando Alegorias da Geometria e da Simetria, respetivamente, mas procurou representar Vénus, a Deusa do Amor, que governa o Mundo (daí o globo), e que é, em si, uma personificação da Beleza, que mede, com um compasso e mirando-se ao espelho oval da Prudência, o balanço ou a exata medida entre o apelo dos prazeres terrenos (representados pelas joias junto do espelho rectangular) e a felicidade conjugal representada pelo cão que a observa. O espelho rectangular reflecte, por sua vez, a figura de costas, bem como a imagem do seu rosto no pequeno espelho oval, e é, de resto, dado numa escala muito pouco frequente na época (para não dizer quase impossível), pelo que se apresenta mais como "pintura dentro da pintura» que nos permite ver a figura principal em toda a sua dimensão simbólica a partir de uma outra perspectiva.

Quanto a nós, Lavinia Fontana, na mesma época em que, como atrás vimos, se terá autorretratado numa das suas últimas gravidezes, introduziu, numa complexa composição mitológica, elementos que remetem para uma clara valorização e exibição do corpo da mulher e dos atributos femininos, que se tornam evidentes na construção da composição, com uma representação especular, a partir de vários planos, do corpo de Vénus ou porventura de uma personificação da própria Pintura, uma vez que a presença do espelho redondo e do compasso na mão da figura corresponde aos atributos da alegoria da Perspectiva na decoração terminal do Arco alegórico dos Pintores, na «Entrada» de Filipe III de Castela (II de Portugal), em 1619, em Lisboa ${ }^{35}$. E fá-lo curiosamente para exaltar não a sensualidade erótica tão em voga nos círculos do Maneirismo internacional, em que a mulher é um sujeito passivo, mas uma problemática que valorizava, dentro do seu ponto de vista de mulher e de mãe, as suas escolhas matrimoniais e sociais.

$\infty<\infty \times \infty \times \infty \times \infty \times \infty \times \infty \times \infty \times \infty \times \infty \times \infty$

34 Ver o tratamento da fortuna crítica e a leitura do quadro, da autoria de Alessandro Zacchi, que são disponibilizados pela casa que comercializa a obra - Maison d'Art, Monte Carlo (www.oldmasters.com) - e que seguimos.

35 O Arco dos Pintores era rematado lateralmente por duas figuras alegóricas sobre plintos, com os respetivos dísticos, da Geometria e da Perspectiva. Ver a reprodução gravada de todos os arcos, muito conhecidos e citados nos meios historiográficos, realizada partir de desenhos de Domingos Vieira Serrão, e a sua minuciosa descrição, na clássica obra de João Baptista Lavanha, Viage de la Catholica Real Magestad del Rei D. Filipe III N. S. al reino de Portugal, Madrid, 1622. 


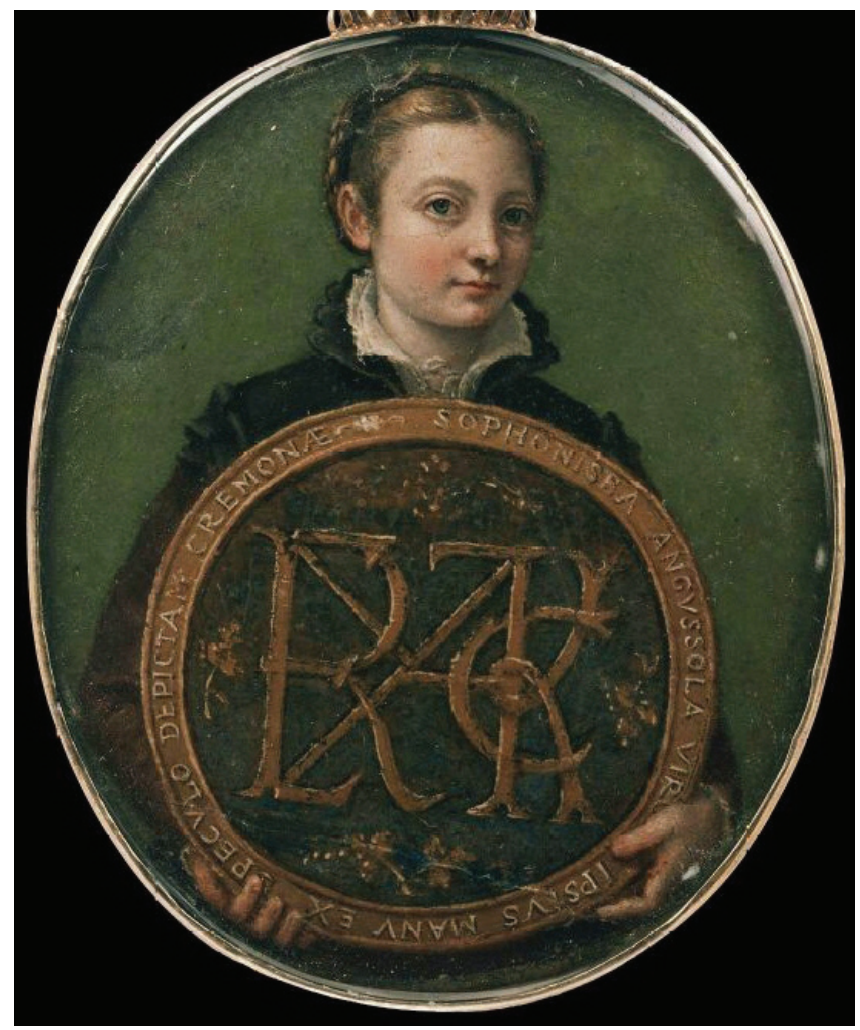

Fig. 1

Sofonisba Anguissola,

Autorretrato em miniatura,

1555-56, Boston,

Museum of Fine Arts

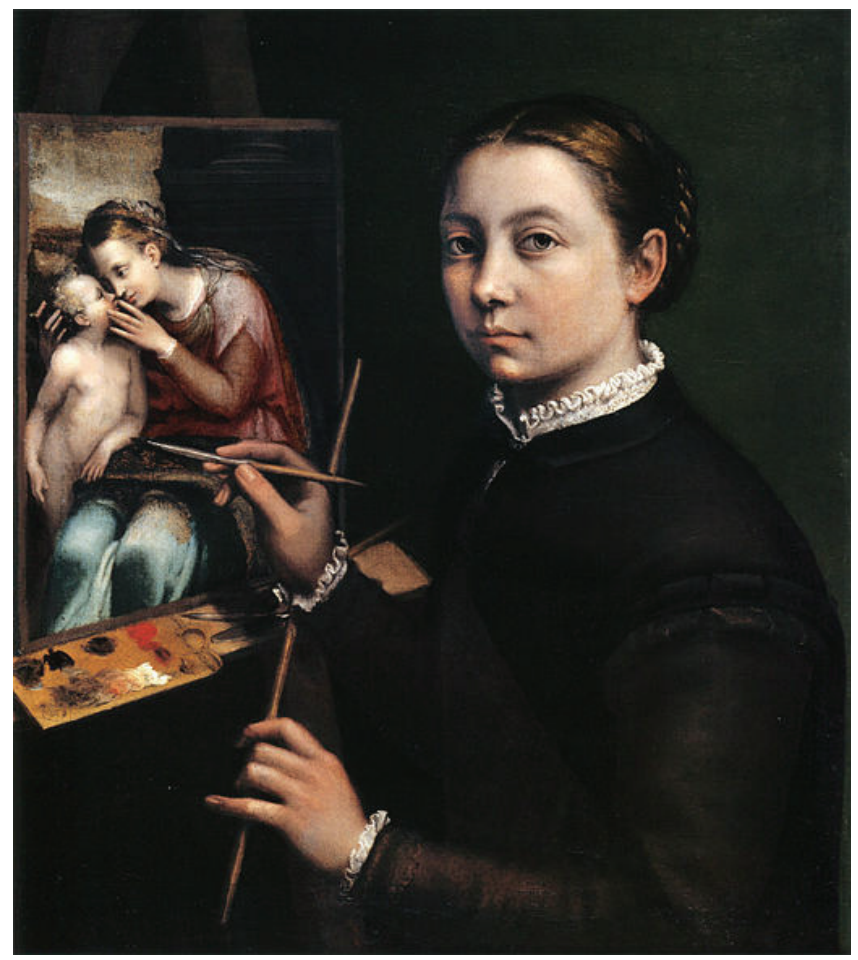

Fig. 2

Sofonisba Anguissola,

Autorretrato ao cavalete, 1556, Lancut, Museu Zamek 


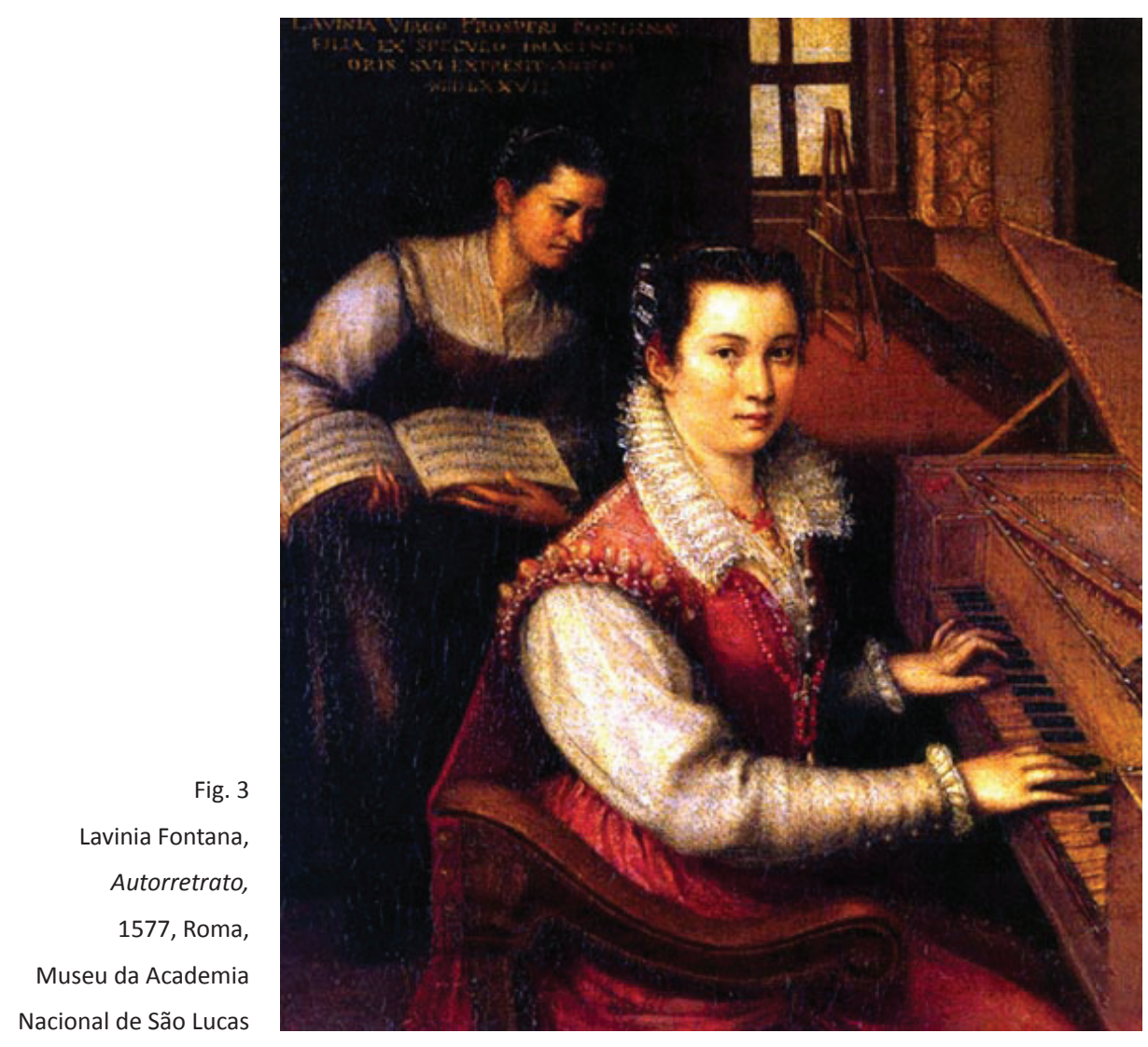

Nacional de São Lucas

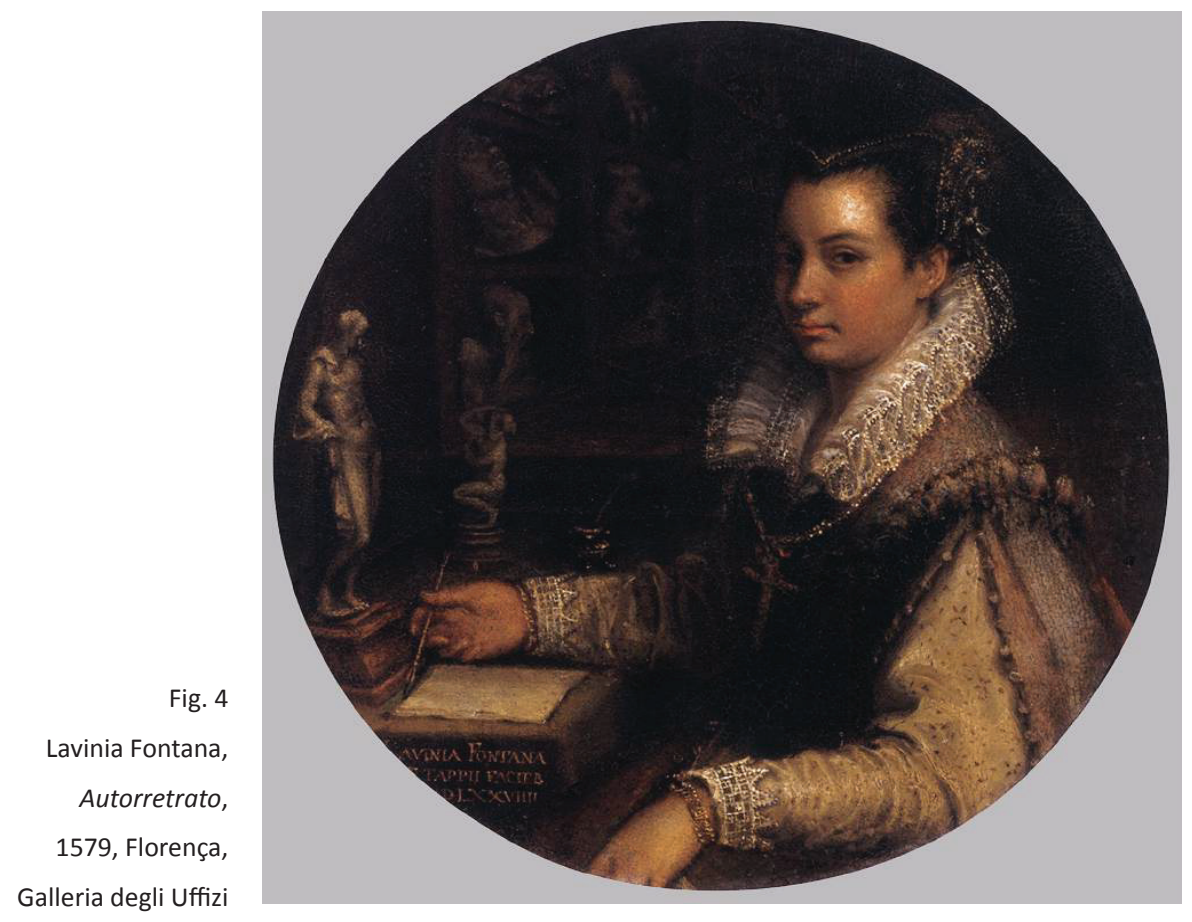




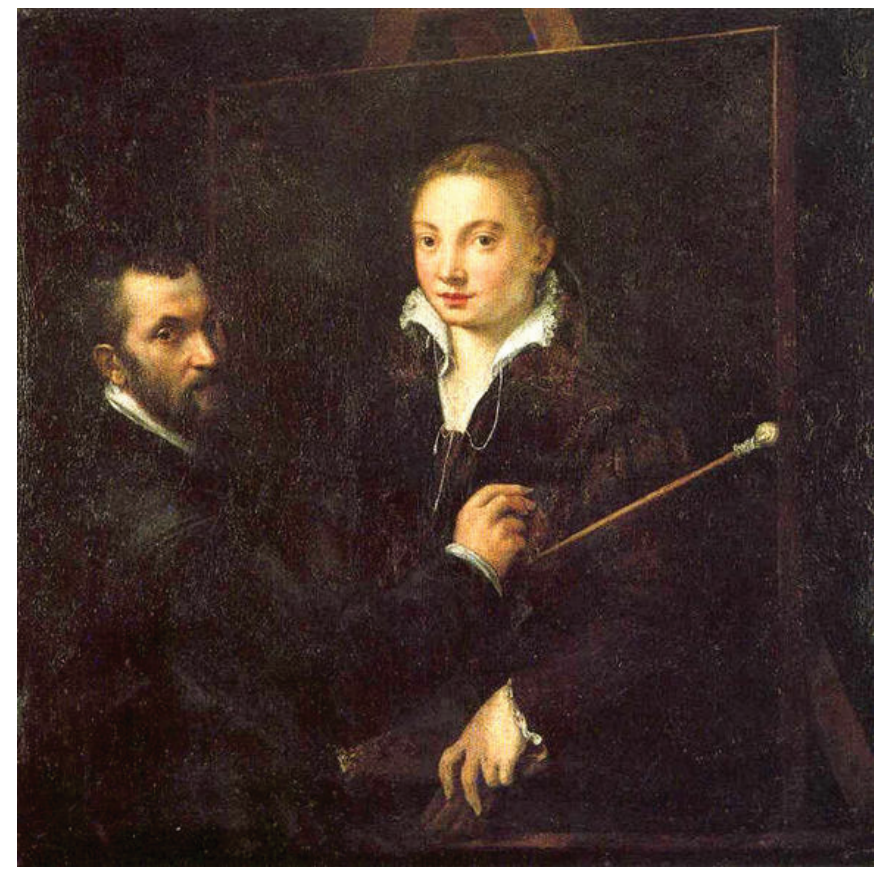

Fig. 5

Sofonisba Anguissola,

Bernardino Campi retrata

Sofonisba Anguissola,

finais da década de 1550,

Siena, Pinacoteca Nacional

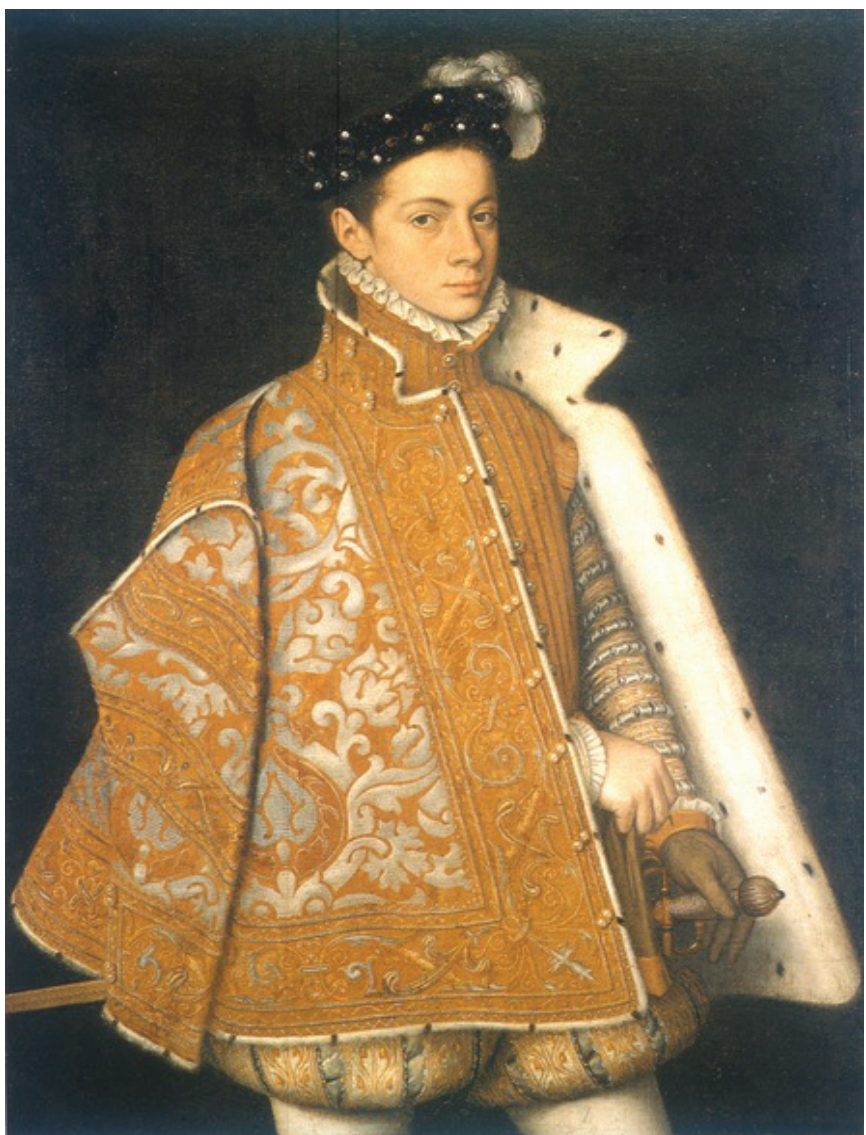

Fig. 6

Sofonisba Anguissola,

Retrato de Alexandre Farnese,

ca 1565-66, Dublin,

National Gallery of Ireland 

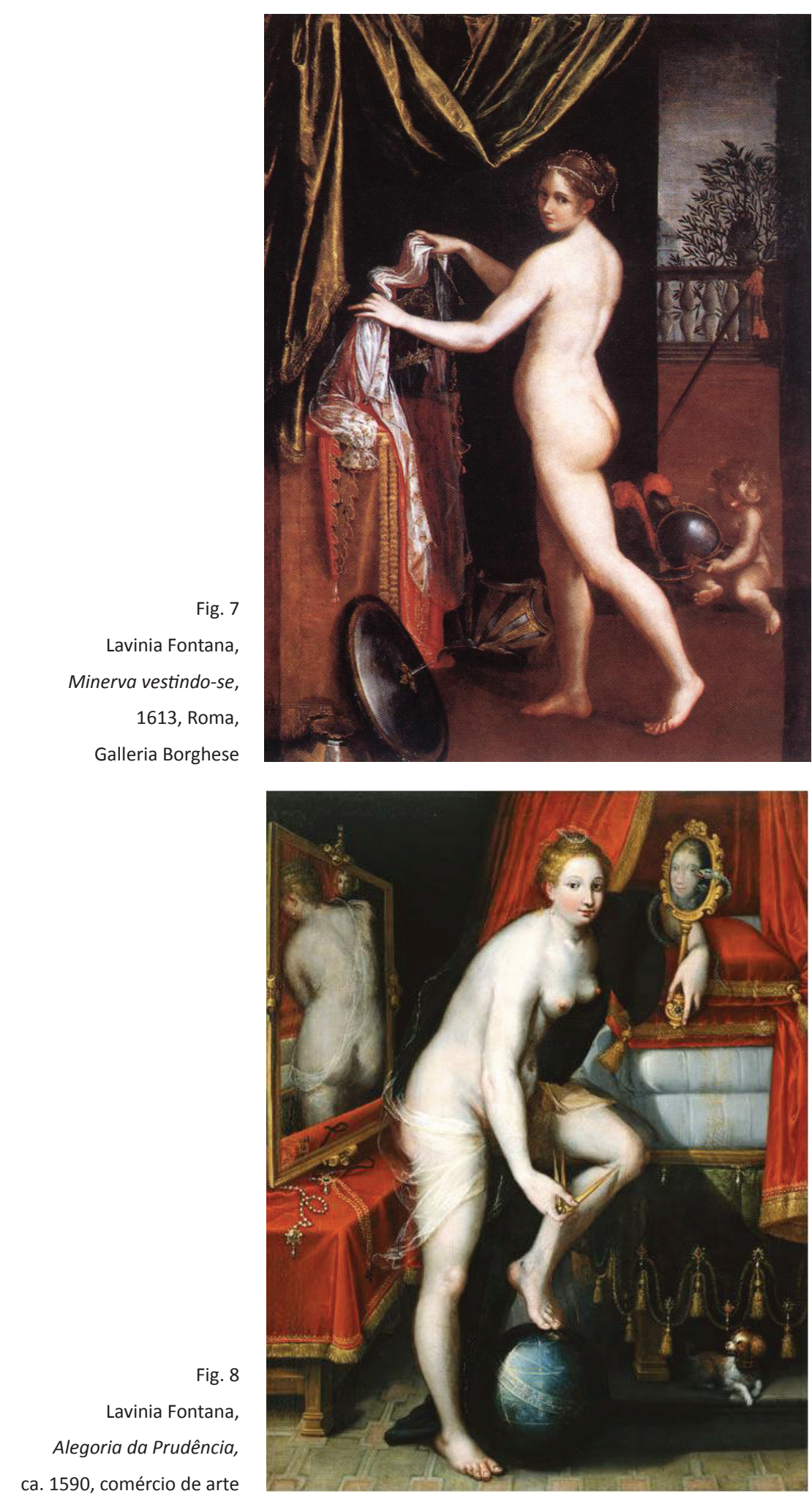